\title{
Observations on the Adsorption of Caulobacter Bacteriophages containing Ribonucleic Acid
}

\author{
Bx JEAN M. SCHMIDT \\ Department of Zoology, University of Edinburgh, \\ West Mains Road, Edinburgh 9, Scotland
}

(Received 24 March 1966)

\begin{abstract}
SUMMARY
Caulobacter bacteriophages containing ribonucleic acid have been found to attach to pili of their hosts. Only when the phage is actually lytic for a given host can the phage + pilus complexes be observed; non-specific complexes are not formed. Removal of the pili from the host by shear treatment before phage adsorption resulted in effective inhibition of phage adsorption. While swarmer caulobacters frequently possessed pili which were located at the flagellated pole of the organism, stalked caulobacters were almost always devoid of these structures. Adsorption experiments with segregated populations of caulobacters indicated that stalked caulobacters adsorbed RNA phages very poorly, while in swarmer populations and unsegregated cultures the RNA phages were efficiently adsorbed.
\end{abstract}

\section{INTRODUCTION}

The demonstration by Crawford \& Gesteland (1964) that R17, a male specific bacteriophage containing ribonucleic acid (RNA), attached to pili of $\mathbf{F}^{+}$and $\mathbf{H f r}$ strains of Escherichia coli drew attention to the processes of RNA-phage adsorption and infection (Brinton, Gemski \& Carnahan, 1964; Bradley, 1965; Brinton, 1965; Valentine, Wedel \& Ippen, 1965; Edgell \& Ginoza, 1965). Among the bacteriophages lytic for Caulobacter species isolated by Schmidt \& Stanier (1965) are several small spherical viruses which contain RNA. It would be of interest to know whether pili to which RNA 'caulophages' can attach occur in caulobacters. The present paper reports an investigation to determine whether the process of RNA-phage adsorption in these stalked bacteria is similar to that observed with $E$. coli + RNA-phage systems, and how stalk formation in caulobacters affects RNA-phage adsorption.

\section{METHODS}

Bacteriophages and hosts. Bacteriophages $\Phi \mathrm{Cb8r}, \Phi \mathrm{Cb} 12 \mathrm{r}$, and $\Phi \mathrm{Cb} 23 \mathrm{r}$, and bacterial strains Caulobacter bacteroides CB 8 and св 11a, C. crescentus $\mathrm{CB} 2$ and св 15, and C. fusiformis св 27 and св 29 were used in this work. These RNA-phages were isolated and described by Schmidt \& Stanier (1965); the Caulobacter strains originated from the collection of Dr Jeanne Stove Poindexter.

Media. For the propagation of host strains, preparation of phage lysates, and adsorption experiments, the standard complex caulobacter medium (PYE) was used (Poindexter, 1964).

Lysate preparation and partial purification of bacteriophages. Lysates were pre- 
pared by eluting phages from confluently lysed PYE agar overlayers. The lysates were concentrated and partially purified by two cycles of differential centrifugation (Schmidt \& Stanier, 1965).

Preparation for electron microscopy. PYE broth cultures of Caulobacter strains were grown at $30^{\circ}$ without shaking to the late exponential phase of growth. Two ml. of the culture were sedimented by centrifugation at $7000 \mathrm{~g}$, and to the bacterial pellet were added $2 \mathrm{ml}$. of a phage preparation containing $10^{10}$ to $10^{11}$ plaqueforming units (p.f.u.). The bacterial pellet was gently resuspended and phage adsorption allowed to proceed at room temperature for 10-20 min. The adsorption mixture was centrifuged at $7000 \mathrm{~g}$ and the supernatant fluid discarded. The pellet was gently resuspended in distilled water $(1 \mathrm{ml}$.) and prepared for electron microscope observation by the negative staining method (Brenner \& Horne, 1959; Bradley, 1962). The stains used were $2 \%$ sodium phosphotungstate ( $\mathrm{pH} 7 \cdot 0$ ), $2 \%$ sodium tungstate (pH 7.2) and $1 \%$ uranyl acetate $(\mathrm{pH} 4 \cdot 0)$. Specimens were placed on Formvarcoated carbon-stabilized grids and examined with a Siemens Elmiskop I electron microscope operated at $60 \mathrm{kV}$.

Shear treatment. The blending procedure for removal of bacterial pili (Brinton, 1965; Valentine et al. 1965) was used with Caulobacter bacteroides CB 11a and C. fusiformis $\mathrm{CB} 27$. The bacterial cultures were subjected repeatedly to $2 \mathrm{~min}$. periods of blending at $4^{\circ}$ by using a pre-cooled MSE Atomix blender at maximum speed. Each shear treatment was followed by centrifugation at $7000 \mathrm{~g}$; the bacterial pellet was then resuspended in fresh medium. After the final centrifugation, the sheared bacteria were resuspended in PYE broth to the volume of the original culture and used in phage adsorption experiments.

Segregation of Caulobacter cultures. The two morphologically distinct types of caulobacter cells, swarmers and those with stalks, can be segregated to obtain relatively homogeneous populations. The centrifugal method of Stove \& Stanier (1962) was used to obtain segregated populations of $C$. bacteroides CB 11a and $C$. fusiformis CB 27. Four successive centrifugations, employing a Servall Superspeed with SS-34 rotor at gravitational fields of 1000 to $1500 \mathrm{~g}$, gave adequate segregation of these strains.

Measurement of adsorption. Caulobacter cultures containing about $5 \times 10^{9}$ colonyforming units $/ \mathrm{ml}$. in PYE broth supplemented with $0.004 \mathrm{M}-\mathrm{MgSO}_{4}$ were preincubated for $5 \mathrm{~min}$. at $30^{\circ}$ on a slow rotary shaker. Phage was then added at a multiplicity of infection of $\mathbf{0 \cdot 0 1}$. At succeeding time intervals, samples were diluted 1/100 in chloroform-saturated PYE broth to stop further adsorption and to eliminate phages which had adsorbed to host caulobacters. Unadsorbed phages were then determined as plaque-forming units by appropriate dilution and plating by the agar overlayer method (Adams, 1959). For calculation of \% unadsorbed phage, the initial phage titre of the adsorption mixture was determined at zero time with omission of the chloroform treatment.

\section{RESULTS}

\section{Lytic activity}

The host ranges of the caulobacter RNA-phages with the hosts used in this study are shown in Table 1. There was no overlap of host specificity among these caulophages; they are also serologically distinct (Schmidt \& Stanier, 1965). 


\section{Observation of phage + pilus complexes}

An electron microscope survey for formation of phage + pilus complexes was made on the RNA-phages in the presence of the various Caulobacter strains. This survey included specific phage + host systems, and also phage + caulobacter mixtures in which the phages did not cause lysis of the Caulobacter strains. In all cases tested, the caulobacter RNA-phages able to cause lysis of a given strain were found to form complexes with pili emanating from the host caulobacters (Table 2). In the nonspecific RNA-phage + caulobacter mixtures, no phage + pilus complexes were observed. No exception to the correlation between ability to cause lysis and formation of phage + pilus complexes has so far been found.

Table 1. Lytic activity of caulobacter RNA-phages

\begin{tabular}{|c|c|c|}
\hline \multicolumn{3}{|c|}{ Caulophage } \\
\hline$\Phi \mathrm{Cb8r}$ & $\begin{array}{c}\Phi \mathrm{Cb12r} \\
\text { Lytic activity }\end{array}$ & $\Phi \mathrm{Cb23r}$ \\
\hline- & + & - \\
\hline- & + & - \\
\hline+ & - & - \\
\hline+ & - & - \\
\hline- & - & + \\
\hline- & - & + \\
\hline
\end{tabular}

* Host strain used in preparation of specific phage lysate.

Table 2. Formation of $R N A$-phage + pilus complexes in caulobacters

C. crescentus $\mathbf{C B} 2$

C. crescentus $\mathrm{CB} 15^{*}$

C. bacteroides $\mathrm{CB} 8$

C. bacteroides CB 11a*

C. fusiformis CB 27*

C. fusifornis CB 29

$\overbrace{\begin{array}{c}\Phi \mathrm{Cb8r} \\ \text { Presence (+) or Absence (-) of phage }+ \\ \text { pilus complex }\end{array}}^{\text {Caulophage }}$

C. crescentus $\mathrm{CB} 2$

C. crescentus CB 15

C. bacteroides $\mathrm{CB} 8$

C. bacteroides $\mathbf{C B} 11 \mathrm{a}$

C. fusiformis $\mathrm{CB} 27$

C. fusiformis Св 29

$\begin{array}{lll}- & + & - \\ - & + & - \\ + & - & - \\ + & - & + \\ - & - & +\end{array}$

Electron micrographs of phage + pilus complexes in which the pili originate from swarmer caulobacters are shown in P1. 1, figs. 1-3. In all three Caulobacter species found to possess pili, these filamentous structures emanated from the flagellated pole of the swarmer; it is this pole which eventually gives rise to stalk development (Poindexter, 1964; Schmidt \& Stanier, 1966). The pili were not found at the opposite non-flagellated pole, nor did they occur at peritrichous sites of origin. The pili occurred on most swarmers of Caulobacter fusiformis, but were observed rather infrequently in $C$. crescentus and $C$. bacteroides. Stalked caulobacters are almost always devoid of pili. In the very few instances where pili were seen on stalked caulobacters, these structures emanated from the terminal end of the stalk (Pl. 2, fig. 4). The 
occurrence of pili on a stalked caulobacter was noted only twice, although many hundreds of stalked caulobacters have been observed in the presence of their specific RNA-phage, and with numerous phage+pili complexes occurring on swarmers present in the same preparation.

In Caulobacter fusiformis, the swarmers usually had several pili; up to 8 pili on one caulobacter were observed (Pl. 1, fig. 1). Caulobacter crescentus and C. bacteroides seldom possessed more than 4 pili/swarmer; more frequently only one pilus or none at all were observed (Pl. 1, figs. 2, 3).

The pili are several microns in length. The usual observable diameter is approximately $40 \AA$ in Caulobacter crescentus $\mathrm{cB} 2$ (Pl. 2, fig. 5) and in C. fusiformis Св 27. No substructure was evident. Occasionally, when several pili were present on a C. fusiformis organism, wider pili with apparent diameters of 75-80 A were observed. These wider forms seemed to have a core penetrated by the negative stain (Pl. 2, fig. 6). The diameter of the pili of C. bacteroides was not reliably determined.

Table 3. $R N A$-phage adsorption with sheared and normal caulobacter cultures

\begin{tabular}{|c|c|c|c|c|c|}
\hline \multirow{3}{*}{$\begin{array}{c}\text { Expt. no. } \\
1\end{array}$} & \multirow{3}{*}{$\begin{array}{c}\text { Caulophage } \\
\Phi \mathrm{Cb} 8 \mathrm{r}\end{array}$} & \multirow{3}{*}{$\begin{array}{l}\text { Caulobacter host } \\
\text { CB 11a }\end{array}$} & \multirow{3}{*}{$\begin{array}{c}\begin{array}{c}\text { Shear } \\
\text { treatment } \\
\text { (2 min.) }\end{array} \\
- \\
\overline{\times 3}\end{array}$} & \multicolumn{2}{|c|}{$\begin{array}{l}\text { Phage remaining } \\
\text { unadsorbed at }\end{array}$} \\
\hline & & & & $7 \min _{(\% \mathrm{u}}$ & $\begin{array}{l}15 \text { min. } \\
\text { rrbed) }\end{array}$ \\
\hline & & & & $\begin{array}{r}53 \\
100\end{array}$ & $\begin{array}{l}20 \\
99\end{array}$ \\
\hline 2 & $\Phi \mathrm{Cb32r}$ & СB 27 & $\overline{\times 3}$ & $\begin{array}{l}43 \\
85\end{array}$ & $\begin{array}{l}17 \\
75\end{array}$ \\
\hline 3 & $\Phi \mathrm{Cb} 23 \mathrm{r}$ & CB 27 & $\overline{\times 4}$ & $\begin{array}{r}54 \\
100\end{array}$ & $\begin{array}{l}\mathbf{2 3} \\
\mathbf{9 7}\end{array}$ \\
\hline
\end{tabular}

\section{Adsorption of caulophages to sheared hosts}

To determine whether RNA-phage adsorption in caulobacters is dependent on the presence of shear-sensitive structures as has been demonstrated for the adsorption of male-specific RNA-phages of Escherichia coli (Brinton, 1965; Valentine et al. 1965), adsorption experiments with sheared and untreated caulobacter cultures were made. Two systems, Caulobacter bacteroides $\mathbf{C B} 11 \mathrm{a}$ and $\Phi \mathrm{Cb8r}$, and $C$. fusiformis св 27 and $\Phi$ Cb23r, were examined. The results are shown in Table 3 . In both systems, host cultures which had undergone shear treatment just before the adsorption experiment were greatly decreased in their capacity to absorb the RNA-phages. With adequate shear treatment, phage adsorption was negligible.

\section{Phage adsorption after chloramphenicol treatment of caulobacters}

Edgell \& Ginoza (1965) showed that R17, a male-specific RNA-phage of Escherichia coli, has an adsorption requirement for metabolically active host organisms. Pre-treatment of the host with chloramphenicol or other metabolic inhibitors prevented irreversible adsorption of phage R17. An analogous situation appears to exist with caulobacter RNA-phage adsorption. Growing cultures of Caulobacter fusiformis Св 27 and C. bacteroides CB 11a were exposed to chloramphenicol (150 $\mu \mathrm{g} . / \mathrm{ml}$.) 
for $2 \mathrm{hr}$, during which time increase in turbidity of the cultures ceased. Phageadsorption experiments were made with chloramphenicol-inhibited cultures and with control cultures. In both phage systems pre-treatment of the host caulobacters with chloramphenicol prevented phage adsorption.

\section{Adsorption of caulophages in segregated host populations}

Because stalked caulobacters had so rarely been observed to possess pili it was of interest to determine how RNA-phage adsorption in populations of stalked caulobacters would be affected by the natural absence of pili. Segregated populations of Caulobacter fusiformis св 27 were more than $90 \%$ homogeneous at the beginning of the adsorption experiment; however, division of stalked caulobacters, giving daughter swarmers did occur during the experiment. Division was not prevented by the addition of a metabolic inhibitor because of the adsorption requirement for metabolically active host caulobacters. Despite the increasing numbers of swarmers, the adsorption of caulophage $\Phi \mathrm{Cb23r}$ was sharply decreased in the stalked caulobacter populations, as compared to that in swarmer populations and in control unsegregated cultures of $C$. fusiformis св 27 (Table 4). Similar results were obtained with caulophage $\Phi \mathrm{Cb8r}$ and segregated $C$. bacteroides cB11a populations.

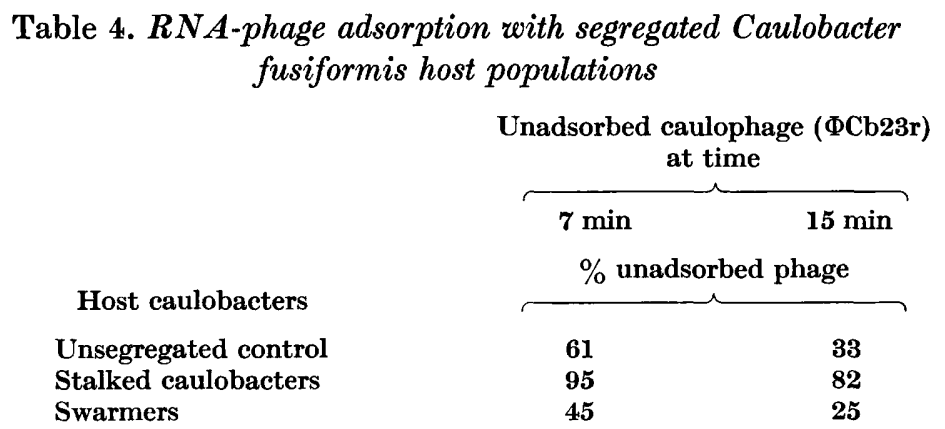

\section{DISCUSSION}

The attachment of caulobacter RNA-phages to pili of their hosts and the dependence of their adsorption upon the presence of these pili are features consistent with the situation described for male-specific RNA-phages of Escherichia coli (Crawford \& Gesteland, 1964; Brinton, 1965; Valentine et al. 1965). Bradley (1965) reported a similar observation for attachment sites of an RNA-phage of Pseudomonas aeruginosa. Thus for all known RNA-phage systems the phage + pilus association is a general characteristic. Brinton (1965) suggested that bacterial pili participate in the conjugation process. It becomes evident that bacteria of the Caulobacter group should be investigated for ability to conjugate, based on the presence in these organisms of RNA-phage + pilus complexes such as occur in $\boldsymbol{E}$. coli and $\boldsymbol{P}$. aeruginosa, which are both known to possess sexuality.

The data presented here do not eliminate the possibility that receptor sites for the caulobacter RNA-phages apart from the pili might exist on the surface of the organisms. However, the sensitivity of RNA-caulophage adsorption to shearing treatment of the host, and the poor phage adsorption with stalked caulobacter 
populations which largely lack pili, implicate the pili as significant phage receptors. The relationship of the phage + pilus association in the actual infection of the caulobacters with viral RNA remains obscure.

Bradley (1965) reported that the pili of Pseudomonas aeruginosa to which RNAphages attach are polar, as found for the pili of the three Caulobacter species studied here. Both the genera Pseudomonas and Caulobacter are characterized by polar flagellation. The diameter of the $P$. aeruginosa pilus is about $40 \AA$ (Bradley, 1966), similar to the diameter observed for most pili of Caulobacter fusiformis and $\boldsymbol{C}$. crescentus. The F pili of $\boldsymbol{E}$. coli are wider, $85 \AA$, and have peritrichous sites of origin (Brinton, 1965). There is a possibility that the few wider pili of $C$. fusiformis which have been observed were actually two pili intertwined, since they have been found only where several pili emanated from the pole of a swarmer and where entanglement of pili was notable. The uneven nature of the negative stain frequently results in apparent variation in the diameter of a pilus. Sodium tungstate was used for negatively-stained preparations of caulophages $\Phi \mathrm{Cb} 8 \mathrm{r}$ and $\Phi \mathrm{Cb} 12 \mathrm{r}$ since these phages disintegrate in sodium phosphotungstate. The phage + pilus complexes were not observable in preparations stained with uranyl acetate, although the phages remained intact.

It had been previously noted in one-step growth experiments that RNA-phages did not multiply in segregated populations of stalked host caulobacters (unpublished data). The very infrequent occurrence of pili on stalked caulobacters, and the poor adsorption of RNA-phages to the stalked caulobacters provide a possible basis for explanation of this observation. The stalked caulobacters may represent a form relatively resistant to RNA-phages which are, however, able to infect the piliated swarmer before it has undergone stalk development.

The author wishes to thank Dr D. E. Bradley for helpful discussion and for the use of facilities in his laboratory. This work was done during tenure of a postdoctoral fellowship from the U.S. National Institutes of Health.

\section{REFERENCES}

Adams, M. (1959). Bacteriophages. New York: Interscience Publishers, Inc.

Bradley, D. E. (1962). A study of the negative staining process. J. gen. Microbiol. 29, 503.

Bradley, D. E. (1965). The morphology and physiology of bacteriophages as revealed by the electron microscope. Jl R. Microsc. Soc. 84, 257.

Bradley, D. E. (1966). The structure and infective process of a Pseudomonas aeruginosa bacteriophage containing ribonucleic acid. J. gen. Microbiol.

Brenner, S. \& Horne, R. W. (1959). A negative staining method for high resolution electron microscopy of viruses. Biochem. biophys. Acta 34, 103.

BRINTon, C. C. (1965). The structure, function, synthesis and genetic control of bacterial pili and a molecular model for DNA and RNA transport in Gram negative bacteria. Trans. N.Y. Acad. Sci. 27, 1003.

Brinton, C. C., Gemski, P. \& Carnahan, J. (1964). A new type of bacterial pilus genetically controlled by the fertility factor of $E$. coli $\mathrm{K} 12$ and its role in chromosome transfer. Proc. natn. Acad. Sci. U.S.A. 52, 776.

Crawford, E. M. \& Gesteland, R. F. (1964). The adsorption of bacteriophage R17. Virology 22, 165.

Edgell, M. H. \& Ginoza, W. (1965). The fate during infection of the coat protein of the spherical bacteriophage R17. Virology 27, 23. 

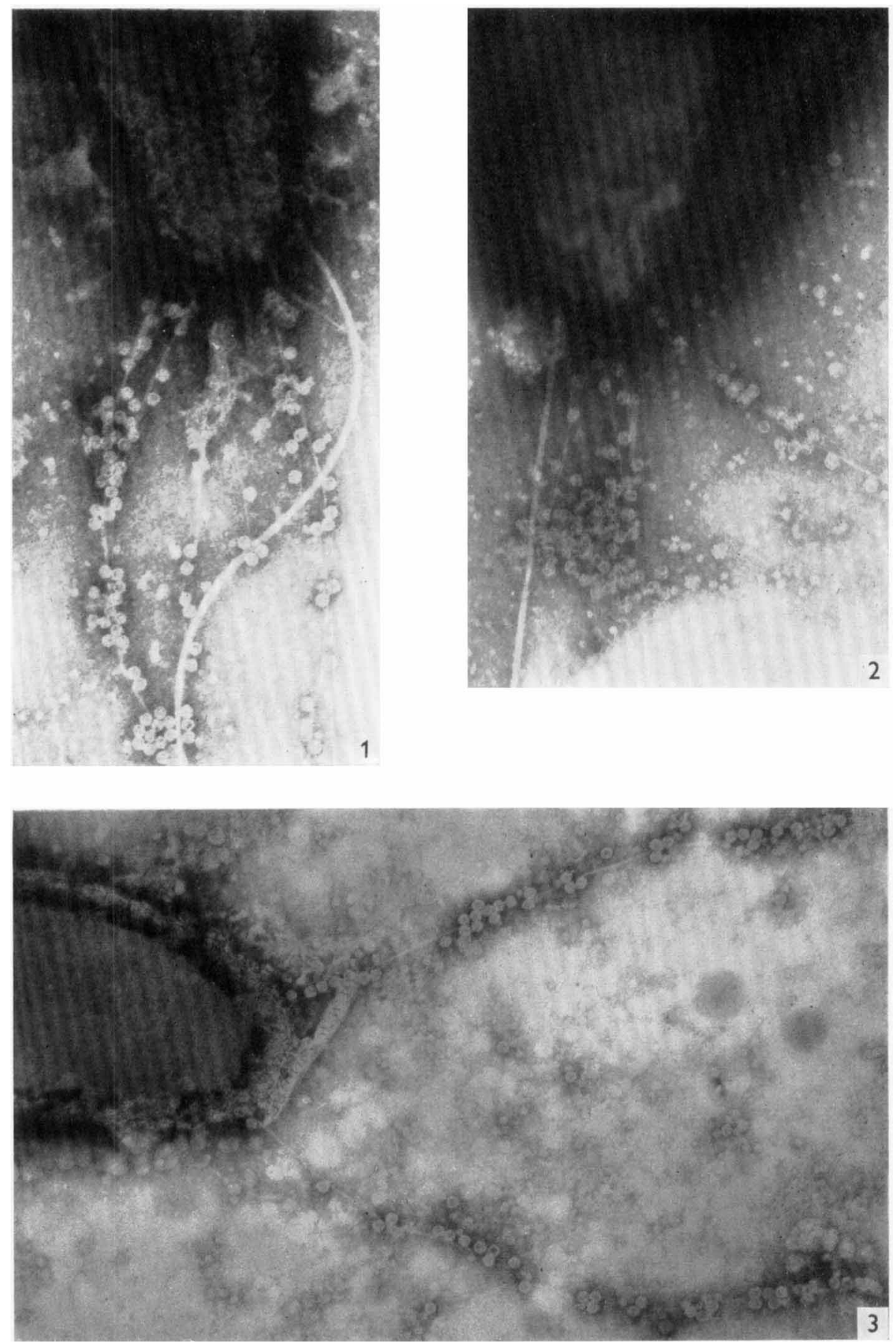

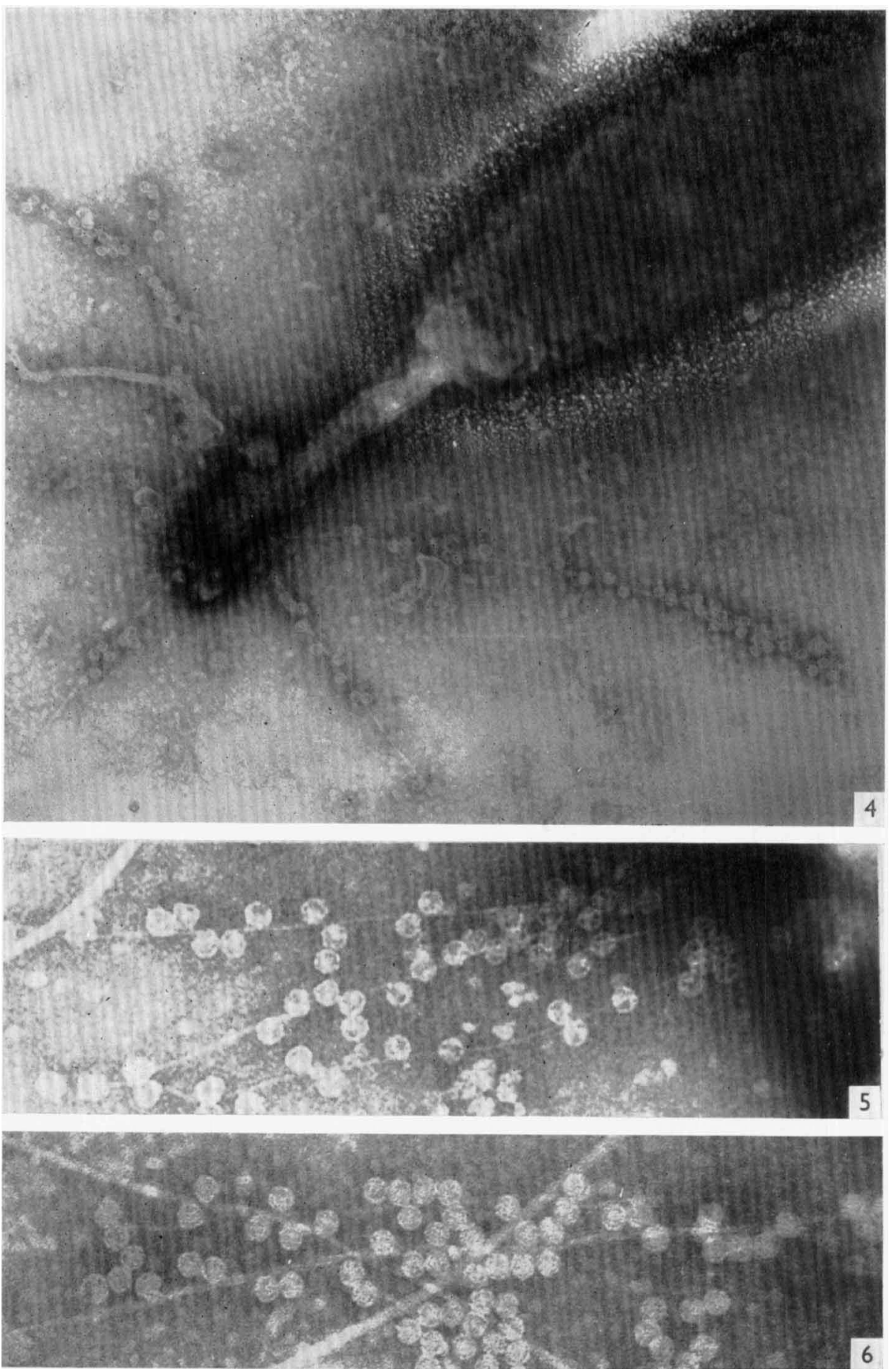
Poindexter, J.S. (1964). Biological properties and classification of the Caulobacter group. Bact. Rev. 28, 231.

Schmidt, J. M. \& Stanier, R. Y. (1965). Isolation and characterization of bacteriophages active against stalked bacteria. J. gen. Microbiol. 39, 95.

Schmidt, J. M. \& Stanier, R. Y. (1966). The development of cellular stalks in bacteria. J. cell. Biol. 28, 423.

Stove, J. L. \& Stanier, R. Y. (1962). Cellular differentiation in stalked bacteria. Nature, Lond. 196, 1189.

Valentine, R. C., Wedel, H. \& Ippen, K. A. (1965). F-pili requirement for RNA bacteriophage adsorption. Biochem. biophys. Res. Comm. 21, 277.

\section{EXPLANATION OF PLATES}

Plate 1

Figs. 1-3. Caulobacter swarmers with RNA-phage attachment to pili. Sodium tungstate stain. $\times 68,000$.

Fig. 1. C. fusiformis $\mathrm{CB} 27$ and caulophage $\Phi \mathrm{C} f 23 \mathrm{r}$.

Fig. 2. C. crescentus $\mathrm{CB} 2$ and caulophage $\Phi \mathrm{Cb12r}$.

Fig. 3. C. bacteroides $\mathrm{cB} 11 \mathrm{a}$ and caulophage $\Phi \mathrm{Cb8r}$.

\section{Plate 2}

Fig. 4. C. fusiformis $\mathrm{CB} 27$ stalked organisms and caulophage $\Phi$ Cb23r. Sodium tungstate stain. $\times 68,000$.

Fig. 5. Pili of $C$. crescentus $\mathrm{CB} 2$ and caulophage $\Phi$ Cb12r. Sodium tungstate stain. $\times 144,000$.

Fig. 6. Pili and flagellum of $C$. fusiformis $\times 144,000$. 